\title{
Liberalización comercial y crecimiento económico en Centroamérica
}

\section{Juan Carlos Moreno-Brid \\ jcmoreno@un.org.mx}

\section{Esteban Pérez}

eperez@eclacpos.org

Sedes Subregionales de la CEPAL

en México y Puerto España
En el presente artículo se examina la relación de largo plazo entre el desempeño de las exportaciones y el crecimiento económico en tres países de Centroamérica durante el período 1950-1999. No se incluye, por lo tanto, el reciente período 2000-2002 de desaceleración de la economía mundial. El análisis de cointegración sirve de fundamento a la opinión de que el sector externo ha sido un factor determinante de la tasa de expansión económica de largo plazo en estos países. En el artículo también se señala que las experiencias de liberalización del comercio llevadas adelante desde mediados de la década de 1980 han tenido impactos muy diversos sobre las tasas de expansión económica de largo plazo de los países considerados. Por último, se analiza la incidencia de estos resultados en las estrategias de liberalización del comercio y el posible impacto de un Acuerdo de Libre Comercio de Centroamérica y Estados Unidos. 


\section{I}

\section{Introducción}

Al igual que en muchas otras economías en desarrollo, en los países de Centroamérica se adoptó, después de la segunda guerra mundial, una estrategia de desarrollo fundada en la industrialización mediante la sustitución de importaciones y en un crecimiento económico guiado por el Estado. Esta estrategia propició la expansión económica de la región durante varias décadas. Sin embargo, fue perdiendo fuerza a medida que se cumplieron las primeras fases de sustitución de importaciones sin que se estableciera en esos países una industria fuerte de bienes de capital, capaz de competir en el ámbito internacional. Hacia fines de la década de 1970, la estrategia de sustitución de importaciones llegó a su límite y la región se vio enfrentada a un aumento cada vez más marcado del déficit fiscal, una severa inflación, la escasez del suministro y, en definitiva, a severas crisis de balanzas de pagos conjuntamente con una recesión económica.

La década de 1980, la "década perdida" en el desarrollo económico de América Latina, estuvo marcada por una serie de intentos por corregir estos desequilibrios macroeconómicos en vista de las serias limitaciones para acceder al crédito externo y a los mercados de capital. Se aplicaron programas de estabilización radical y de ajuste estructural dirigidos a reducir la inflación y corregir desequilibrios fiscales. Dos elementos importantes de tales programas fueron la adopción de políticas de liberalización del comercio, para disminuir las barreras arancelarias y no arancelarias, y la reducción del tamaño del sector público.

Estos programas tuvieron éxito en bajar la inflación y corregir los desequilibrios fiscales en la mayor parte de la región. Además, produjeron un cambio en la composición de las exportaciones, sobre todo en Costa Rica y El Salvador, países cuyas exportaciones

\footnotetext{
$\square$ Versiones anteriores de este trabajo fueron presentadas en el XXIII Congreso Internacional de la Asociación de Estudios Latinoamericanos (LASA 2001), que se llevó a cabo en Washington D.C. del 6 al 8 de septiembre de 2001, y en el encuentro de la Red de Diálogo Macroeconómico (REDIMA) que se realizó en noviembre de 2002 en la sede de la CEPAL, en Santiago de Chile. Los nombres de los autores aparecen en orden alfabético. Las opiniones expresadas en este artículo son de exclusiva responsabilidad de sus autores y pueden no coincidir con las de las Naciones Unidas. Los autores agradecen los comentarios de un juez anónimo y del Director de la Revista de la CEPAL.
}

aumentaron a un ritmo extraordinario en el decenio de 1990. Sin embargo, a pesar de tan pronunciado impulso exportador, la expansión económica de Centroamérica en ese decenio fue más débil que en 1950-1970, años culminantes del período de sustitución de importaciones (cuadro 1). Este contraste también surge cuando se incluyen en el análisis las tasas de expansión demográfica. En efecto, el producto interno bruto (PIB) real per cápita de Centroamérica creció a una tasa media anual de $1,1 \%$ en la década de 1990 , significativamente inferior a las de $2,9 \%$ y de $1,7 \%$ registradas respectivamente en las décadas de 1960 y $1970 .^{1}$

La deslucida evolución económica de Centroamérica no contribuyó a mejorar las condiciones sociales de la población. Su deficiente desempeño durante el decenio de 1980 deterioró aún más esas condiciones. Excepto en Costa Rica, más del 50\% de la población centroamericana vive por debajo de la línea de pobreza o en condiciones de pobreza extrema.

La búsqueda de estrategias alternativas para mejorar el bienestar de su población llevó a las economías centroamericanas, a partir del decenio de 1990 y en algunos casos desde mediados del de 1980, a intensificar su orientación hacia el exterior y a profundizar sus lazos comerciales con sus vecinos del norte. En 1994 y 1997 las autoridades de Costa Rica y Nicaragua firmaron acuerdos de libre comercio con México. En 2000 las de El Salvador, Guatemala y Honduras (el llamado Triángulo del Norte) siguieron el ejemplo y, más recientemente, las de Costa Rica firmaron un acuerdo de libre comercio con Canadá. Si bien estos acuerdos pueden estimular las exportaciones y por ende el crecimiento económico, no ayudan a cumplir con la meta de los gobiernos de Centroamérica de acceder al mercado de Estados Unidos en pie de igualdad con respecto al Tratado de Libre Comercio de América del Norte (TLC), es decir, en las mismas condiciones que México y Canadá en lo relativo a las restricciones arancelarias y no arancelarias. Tal como hoy se plantea, la Iniciativa para la Cuenca del Caribe compensa en parte esa deficiencia, al permitir que los textiles y otros productos específicos tengan un acceso preferencial al mercado de Estados Unidos.

\footnotetext{
${ }^{1}$ Véase Bulmer-Thomas y Kincaid (2000).
} 
CUADRO 1

Centroamérica: Crecimiento del PIB, 1950-1999

\begin{tabular}{|c|c|c|c|c|c|c|}
\hline \multirow[t]{2}{*}{ País } & \multicolumn{6}{|c|}{ Períodos } \\
\hline & 1950-99 & $1950-60$ & $1960-70$ & $1970-80$ & $1980-90$ & $1990-99$ \\
\hline Costa Rica & 4,9 & 6,6 & 6,0 & 5,5 & 2,1 & 5,0 \\
\hline El Salvador & 3,5 & 4,8 & 5,4 & 3,0 & $-0,8$ & 4,6 \\
\hline Guatemala & 3,7 & 3,7 & 5,0 & 5,4 & 0,9 & 4,1 \\
\hline Honduras & 3,7 & 2,9 & 4,7 & 5,2 & 2,2 & 3,1 \\
\hline Nicaragua & 3,1 & 5,5 & 6,1 & 0,8 & $-0,8$ & 3,2 \\
\hline
\end{tabular}

Fuente: Elaborado por los autores con datos proporcionados por la CEPAL.

Actualmente, bajo el influjo del TLC de América del Norte, las autoridades centroamericanas están negociando un acuerdo de libre comercio con Estados Unidos y el resto de las Américas, para un futuro no muy lejano. Las economías pequeñas ven en esta iniciativa un instrumento fundamental para dar impulso a sus posibilidades de crecimiento. Según se prevé, el Área de Libre Comercio de las Américas (ALCA) no sólo aumentaría las exportaciones intrahemisféricas, sino que también atraería a Centroamérica la inversión extranjera directa. Un rasgo importante de la iniciativa del ALCA sería el acuerdo para tomar en cuenta "las diferencias en los niveles de desarrollo y el tamaño de las economías de nuestro hemisferio para crear oportunidades para la plena participación de las economías más pequeñas y aumentar su nivel de desarrollo". ${ }^{2}$ El reconocimiento de esas diferencias estructurales constituiría para las economías más pequeñas un principio rector clave para orientar sus iniciativas y reclamos en el proceso de negociación comercial.

En este artículo se analiza la relación entre la evolución de las exportaciones y el crecimiento económico en tres países de Centroamérica, teniendo como punto de partida la idea de que la balanza de pagos constituye una restricción fundamental para la tasa de expansión económica de largo plazo de los países en desarrollo. ${ }^{3}$ Sobre la base de los resultados empíricos obtenidos, se extraen consecuencias para los acuerdos comerciales y las posibilidades de liberalización del comercio.

\footnotetext{
2 Véase Cuarta Reunión Ministerial de Comercio, Cumbre de las Américas (1998) y Quinta Reunión Ministerial de Comercio, Área de Libre Comercio de las Américas (1999).
}

Uno de los supuestos principales de esta perspectiva de análisis, en su versión más simplificada, es que la diferencia entre la tasa de crecimiento de un país dado y la del resto del mundo es proporcional a la razón de sus respectivas elasticidades ingreso de importaciones y exportaciones. En pocas palabras, el modelo establece que, a igualdad de las demás condiciones, la tasa de crecimiento de un país dado, en el largo plazo, se apartará de la del resto del mundo si la elasticidad ingreso de las importaciones del país es mayor que la elasticidad ingreso en el resto del mundo para sus exportaciones.

Este artículo se divide en seis secciones. Tras la presente introducción, en la sección II se expone brevemente el modelo teórico adoptado en este artículo (en la versión de A.P. Thirlwall de comienzos de la década de 1980), y que P. Krugman denominara posteriormente regla de los 45 grados. En la sección III se presentan los criterios metodológicos y las técnicas econométricas de largo plazo que se han empleado aquí. En la sección IV se aplican esas técnicas para derivar las elasticidades del comercio exterior. En la sección V se analiza la trayectoria de las elasticidades ingreso de las importaciones y exportaciones a lo largo del tiempo y se vinculan esos resultados con las negociaciones sobre libre comercio y las políticas de liberalización del comercio. La sección VI, por último, plantea la conclusión y las reflexiones finales.

\footnotetext{
3 El modelo fue ideado por Thirlwall (1979). Por su parte, McCombie y Thirlwall (1997), Moreno-Brid (1998-99 y 2001) y Barbosa (2002) han hecho aportes recientes a esta perspectiva teórica.
} 


\section{II}

\section{Un modelo teórico para el análisis de la liberalización del comercio y el crecimiento}

En el modelo de Thirlwall se afirma, sobre el supuesto de que un país no puede recurrir al capital extranjero para financiar indefinidamente su déficit comercial y que no hay influencias de la relación de intercambio o de otros efectos de los precios, que la razón de crecimiento del ingreso de un país dado respecto de la del resto del mundo es igual a la razón entre la elasticidad ingreso de las exportaciones del resto del mundo y la elasticidad ingreso de las importaciones de ese país. La expresión sería:

$$
y_{b} / y_{w}=\pi / \xi
$$

donde:

$y_{b}=$ tasa de crecimiento del ingreso interno, en términos reales $(d y / y)$.

$y_{w}=$ tasa de crecimiento del resto del mundo, en términos reales $(d w / w)$.

$\pi=$ elasticidad ingreso de las exportaciones

$\xi=$ elasticidad ingreso de las importaciones

La ecuación [1] se obtiene fácilmente como solución al sencillo modelo comercio-crecimiento dado por las siguientes tres ecuaciones:

$$
\begin{aligned}
& d x / x=\eta\left(d p / p-d p^{*} / p^{*}\right)+\pi d w / w \\
& d m / m=\phi\left(d p^{*} / p^{*}-d p / p\right)+\xi d y / y \\
& d p^{*} / p^{*}+d m / m=(d p / p+d x / x)
\end{aligned}
$$

donde las ecuaciones [2] y [3] son las funciones estándar de demanda para las exportaciones e importaciones, pero expresadas en términos de sus tasas de crecimiento, siendo $x$ las exportaciones reales, $m$ las importaciones reales, $p$ los precios internos, $p^{*}$ los precios externos, $w$ el ingreso real en el mundo, $y$ el ingreso interno en términos reales, $\eta<0$ y $\pi>0$ las elasticidades precio e ingreso de las exportaciones, y $\phi<0 y \xi>0$ las respectivas elasticidades de las importaciones. A los efectos de una exposición sencilla, se considera que el tipo de cambio nominal es fijo e igual a uno. La ecuación [4] es la expresión dinámica de una identidad de la balanza de pagos que establece que, en el largo plazo, las exportaciones y las importaciones deben alcanzar un equilibrio (es decir, el déficit del comercio debe eliminarse, siendo $X=M$ ). La solución del sistema de las ecuaciones [2] a [4] conduce a la siguiente expresión de la tasa de crecimiento de la economía en el largo plazo $y_{b}$ :

$$
\text { [5] } y_{b}=\frac{\pi d w / w+(\eta+\phi+1)(d p / p-d p * / p *)}{\xi}
$$

Y, si la condición Marshall-Lerner se cumple, la ecuación [5] se simplifica de esta manera:

$$
y_{b}=\frac{\pi d w / w}{\xi}
$$

y se llega fácilmente a la misma expresión de la ecuación [1] mencionada.

$$
\mathrm{y}_{\mathrm{b}} / \mathrm{y}_{\mathrm{w}}=\pi / \xi
$$

La ecuación [7] indica que si la razón de elasticidades-ingreso del comercio exterior es menos (más) que uno, el ingreso real de la economía local $y_{b}$ aumentará a un ritmo menor (mayor) que el del resto del mundo $y_{w}$.

En este sentido, las consecuencias para los procesos de liberalización del comercio, y en general para los acuerdos regionales de libre comercio, son varias. En primer lugar, una política de liberalización del comercio estimulará el crecimiento económico si ocurre junto con un incremento en la elasticidad ingreso para las exportaciones del país $(\pi)$ por encima de cualquier aumento que pueda causar en la elasticidad ingreso de las importaciones del país $(\xi)$. Este criterio, en la medida en que subraya el impacto sobre el crecimiento económico, puede ofrecer una referencia sencilla para distinguir entre estrategias de liberalización del comercio exitosas y no exitosas. En segundo lugar, en un proceso de integración regional que incluye economías de diferentes tamaños y niveles de desarrollo, una economía de menor desarrollo tenderá, con el transcurso del tiempo, a alcanzar a (apartarse de) las economías industrializadas, si la razón de elasticidad es mayor 
(menor) a uno. En tercer lugar, lo que es más importante aún, si la correspondiente razón de elasticidades es distinta para, digamos, dos grupos de economías en desarrollo, un proceso de integración regional llevará inevitablemente a un proceso de divergencia entre ellas. Algunas economías se verán beneficiadas y alcanzarán a las más avanzadas. Otras quedarán rezagadas y, por lo tanto, correrán el riesgo de aumentar sus niveles de pobreza relativos $\mathrm{y}$, quizás, también absolutos.

\section{III}

\section{Criterios metodológicos}

Para efectuar un análisis empírico de la ecuación [1] se necesita un marco que especifique la función de demanda de importación y exportación de la cual se obtienen las elasticidades ingreso de las exportaciones e importaciones. En este artículo hemos aplicado el enfoque convencional conocido como modelo de sustitutos imperfectos.

Este enfoque se basa en el supuesto de que los bienes nacionales y extranjeros no son sustitutos perfectos. Y, dando por sentada la existencia de una elasticidad infinita de la oferta, se plantea en el modelo que la demanda es lo que fundamentalmente determina las exportaciones e importaciones. Así, se argumenta entonces que los determinantes principales de las importaciones son el ingreso del país importador, el propio precio de las importaciones y el precio interno de los bienes y servicios transables en el ámbito internacional producidos localmente. Del mismo modo, los principales determinantes de las exportaciones son el ingreso del resto del mundo y el precio de los bienes de exportación en relación con el precio de los bienes fabricados en el exterior que compiten con ellos en el mercado internacional. Además, se asume generalmente que la ilusión monetaria no existe y se impone una restricción de homogeneidad cero para garantizar que las elasticidades precio externas e internas de la demanda de importación (exportación) tienen la misma magnitud en términos absolutos.

Los supuestos del modelo de sustitutos imperfectos validan el uso de métodos econométricos de ecuación simple para calcular la evolución del comercio exterior de un país. ${ }^{4}$ Expresadas en un logaritmo, las especificaciones estándares de la demanda de importación y exportación son:

${ }^{4}$ Goldstein y Kahn (1985) plantean la visión estándar de estos modelos.
[8] $\ln \left(m_{t}\right)=a_{0}+a_{y} \ln \left(y_{t}\right)+a_{p} \ln \left(P m_{t} / P d_{t}\right)+u_{t}$

[9] $\ln \left(x_{t}\right)=b_{0}+b_{y} \ln \left(y_{t}^{*}\right)+b_{p} \ln \left(P x_{t} / P^{*}{ }_{t}\right)+v_{t}$

donde $u_{t}$ y $v_{t}$ representan la perturbación de ruido blanco, $m_{t}$ son las importaciones reales e $y_{t}$ es el ingreso interno real del país importador. $P d_{t}$ y $P m_{t}$ son, respectivamente, los índices de precios internos de la producción local transable, y los de bienes y servicios importados expresados en moneda local. De acuerdo con esto, $P x_{t}$ y $P{ }_{t}$ son los índices de precios correspondientes de exportaciones y de bienes del exterior. En ambas ecuaciones los precios se expresan en unidades de la respectiva moneda local. Los parámetros $a_{y}, b_{y}$ corresponden a las elasticidades ingreso de largo plazo de la demanda de importación y exportación, y $a_{p}$, $b_{p}$ corresponden a sus elasticidades precio de largo plazo.

Nótese que, dado que la idea central del artículo es la evolución del comercio exterior en el largo plazo, las ecuaciones [8] y [9] ignoran influencias a corto plazo (rezagadas) de ingreso y precios relativos sobre la demanda de importación y de exportación. ${ }^{5}$ Por lo tanto, los coeficientes de las dos ecuaciones lineales logarítmicas reflejan los multiplicadores de largo plazo de ingreso y precio de las exportaciones e importaciones.

El análisis empírico de las relaciones económicas de largo plazo debe tener en cuenta las propiedades potenciales no estacionarias de los datos. Es decir, debe reflejar el hecho de que los procesos de la serie de tiempo pueden no tener una media constante o una variancia

\footnotetext{
${ }^{5}$ Debe destacarse que este concepto de equilibrio de largo plazo no supone una trayectoria de crecimiento de steady state. Esta última implica una elasticidad ingreso de la demanda unitaria para mantener una razón constante entre las importaciones (o exportaciones) y el ingreso en la posición de steady state cuando los precios relativos son constantes.
} 
acotada. El método estándar para prever la no estacionariedad en el cálculo de las relaciones económicas de largo plazo es la aplicación de métodos de cointegración. El primer paso de este método exige la verificación de que las variables relevantes tienen órdenes de integración compatibles, ${ }^{6}$ lo que se lleva a cabo en este artículo mediante la aplicación de las pruebas Dickey-Fuller convencional y aumentada.

Una vez que se ha verificado esa compatibilidad, el paso siguiente consiste en estimar el número de combinaciones lineales estacionarias (denominadas vectores de cointegración) de las variables pertinentes. Si no se identifica combinación alguna, se dice que las variables no están cointegradas; en otras palabras, que no hay una relación lineal estable de largo plazo entre ellas. Por otro lado, si existe por lo menos una de esas combinaciones, se dice que las variables están cointegradas y se interpretan los coeficientes calculados como los multiplicadores lineales de largo plazo de los regresores pertinentes. Para calcular la cantidad de esos vectores cointegrantes, en caso de que existieran, aplicamos los métodos de Johansen. ${ }^{7}$ Es necesario especificar primero un sistema de vector autorregresivo (VAR) con el conjunto de variables relevantes y luego calcular la cantidad de relaciones de equilibrio de largo plazo entre ellas.

\section{IV}

\section{Demanda de largo plazo de importación y exportación de Centroamérica}

\section{Origen de los datos}

Los autores derivaron los datos empleados aquí para calcular las funciones de importación y exportación de Guatemala, Costa Rica y El Salvador, utilizando cifras oficiales de los bancos de datos de la cepal y del Fondo Monetario Internacional (FMI) correspondientes al período comprendido entre 1950 y 1999. Las cifras del producto interno bruto $y$, de importaciones $m$ y de exportaciones $x$ se miden a precios constantes en unidades de moneda local. Tanto las exportaciones como las importaciones incluyen el comercio de bienes y servicios. Siguiendo los procedimientos estándares, las variables relativas de precio $P m_{t} / P d_{t}$ en la ecuación [8] y $P x_{t} / P^{*}$ en la ecuación [9], se sustituyeron por la tasa de cambio real definida como la razón entre el índice de precios al consumidor de cada país centroamericano y el de Estados Unidos, medida en unidades de moneda local. Dado que las exportaciones de Centroamérica se destinan principalmente a Estados Unidos, el ingreso nacional estadounidense, medido en términos reales, se empleó como estimación del ingreso del mundo en el análisis econométrico de la demanda de exportación.

\footnotetext{
${ }^{6} \mathrm{El}$ orden de integración de una variable estocástica $X(t)$ se define como la cantidad de veces que debe aplicarse un diferencial de primer orden para obtener una serie estacionaria.
}

\section{Resultados empíricos}

Como se ha señalado, el primer paso en el análisis econométrico de la demanda de importación y exportación de largo plazo fue aplicar las pruebas de DickeyFuller y de Dickey-Fuller aumentada (DF y DFA) para evaluar las propiedades estacionarias de la serie de tiempo considerada en las ecuaciones [8] y [9] durante el período 1950-1999. Se emplearon el criterio de información de Akaike (AIC) y el criterio de Schwarz con el fin de elegir el rezago óptimo $k$ para las pruebas DFA. Los resultados indican que, para cada país, los niveles logarítmicos del PIB real, las importaciones reales, las exportaciones reales y la tasa de cambio real son procesos I(1) y sus primeras diferencias son procesos $\mathrm{I}(0)$ (cuadro 2).

Además, se halló que el nivel logarítmico del ingreso nacional de Estados Unidos en términos reales es un proceso $\mathrm{I}(1)$, y su primera diferencia, un proceso $\mathrm{I}(0)$ (cuadro 2). En cada caso, los criterios de selección del modelo indicaron un rezago óptimo de un año para los sistemas de vectores autorregresivos (VAR) sin restricciones de importaciones y exportaciones (cuadro 3 ). ${ }^{8}$

\footnotetext{
${ }^{7}$ Puede encontrarse una introducción sencilla a la prueba de raíz unitaria y al análisis cointegrado en Cuthbertson y otros (1992), Charemza y Deadman (1992) y Enders (1995).

${ }^{8}$ Algunas ecuaciones individuales de los sistemas var de demanda de importación para El Salvador y Guatemala y de demanda de
} 
CUADRO 2

Tres países centroamericanos: Pruebas de raíz unitaria Dickey-Fuller (DF) y Dickey-Fuller aumentada (DFA), 1950-1999a

\begin{tabular}{|c|c|c|c|}
\hline \multirow[t]{2}{*}{ País } & \multirow[t]{2}{*}{ Variable } & \multicolumn{2}{|c|}{$\mathrm{DF}(\mathrm{DFA})$} \\
\hline & & $\mathrm{AC}$ & $\mathrm{SC}$ \\
\hline \multirow[t]{8}{*}{ Costa Rica } & LGDP & $-2,4$ & $-2,4$ \\
\hline & $\triangle \mathrm{LGDP}$ & $-6,4^{b}$ & $-6,4^{b}$ \\
\hline & LX & $-2,4$ & $-2,4$ \\
\hline & $\Delta \mathrm{LX}$ & $-7,7^{\mathrm{b}}$ & $-7,7^{b}$ \\
\hline & LM & $-2,6$ & $-2,6$ \\
\hline & $\Delta \mathrm{LM}$ & $-5,2^{b}$ & $-5,1^{b}$ \\
\hline & LRER & $-2,5$ & $-2,5$ \\
\hline & $\triangle \mathrm{LRER}$ & $-7,2^{b}$ & $-7,2^{b}$ \\
\hline \multirow[t]{8}{*}{ El Salvador } & LGDP & $-2,2$ & $-2,2$ \\
\hline & $\Delta \mathrm{LGDP}$ & $-3,3^{b}$ & $-3,3^{b}$ \\
\hline & LX & $-2,0$ & $-1,2$ \\
\hline & $\Delta \mathrm{LX}$ & $-6,2^{b}$ & $-6,2^{b}$ \\
\hline & LM & $-2,3$ & $-2,3$ \\
\hline & $\Delta \mathrm{LM}$ & $-5,2^{b}$ & $-5,2^{b}$ \\
\hline & LRER & $-0,92$ & $-2,2$ \\
\hline & $\triangle$ LRER & $-3,0^{\mathrm{b}}$ & $-8,3^{b}$ \\
\hline \multirow[t]{8}{*}{ Guatemala } & LGDP & $-2,2$ & $-1,8$ \\
\hline & $\triangle \mathrm{LGDP}$ & $-3,4^{b}$ & $-3,4^{b}$ \\
\hline & LX & $-2,6$ & $-2,6$ \\
\hline & $\Delta \mathrm{LX}$ & $-5,4^{b}$ & $-5,4^{b}$ \\
\hline & $\mathrm{LM}$ & $-2,6$ & $-2,6$ \\
\hline & $\Delta \mathrm{LM}$ & $-4,6^{b}$ & $-5,6^{b}$ \\
\hline & LRER & $-3,8^{b}$ & $-2,3$ \\
\hline & $\triangle$ LRER & $-6,0^{b}$ & $-6,0^{b}$ \\
\hline \multirow[t]{2}{*}{ Estados Unidos } & LNI & $-3,1$ & $-3,1$ \\
\hline & $\Delta \mathrm{LNI}$ & $-6,0^{\mathrm{b}}$ & $-7,0^{\mathrm{b}}$ \\
\hline
\end{tabular}

Fuente: Elaborado por los autores.

a $\Delta X$ representa la primera diferencia $X_{T}-X_{T-l}$. DF y DFA son las pruebas estadísticas de raíz unitaria Dickey-Fuller y Dickey-Fuller aumentada. AC y SC son las estadísticas de criterio de información de Akaike y de criterio de Schwartz.

b Significación a nivel de $5 \%$ de confianza.

El cuadro 4 muestra los resultados del análisis de cointegración de Johansen para la demanda de exportación e importación de los tres países aquí analizados. En cada caso los resultados indican, con una significación a nivel de 5\%, la existencia de un vector de cointegración para la demanda de importación tal como aparece en la ecuación [8]. Nótese además que la magnitud de la elasticidad ingreso de las importacio-

exportación en Guatemala no satisficieron la prueba del multiplicador de Lagrange (LM) para verificar la existencia o ausencia de correlación serial residual en 1950-1999. El problema puede solucionarse mediante la introducción de una variable ficticia que refleje los cambios metodológicos en la incorporación de los datos de las empresas maquiladoras. nes de largo plazo de estas tres economías es similar. Se ubica en el rango de 1,27 a 1,49. Excepto para Guatemala, las elasticidades precio de largo plazo de la demanda de importación no son significativas para un nivel de $5 \%$ de confianza.

En el caso de las exportaciones, los resultados de las pruebas de Johansen para cada uno de estos países no rechazan la hipótesis de la existencia de un solo vector de cointegración. Según estos resultados, Costa Rica tiene la cifra más elevada para la elasticidad ingreso de las exportaciones de largo plazo $(2,64)$ seguida por El Salvador (2,24). La elasticidad ingreso calculada de Guatemala fue muy inferior $(1,07)$. Sin excepción, la elasticidad precio de las exportaciones de largo plazo no fue significativa a nivel de $5 \%$ de confianza.

La falta de una influencia importante de largo plazo del tipo de cambio real en las exportaciones e importaciones de estos tres países centroamericanos puede tener diversas causas. Una causa posible es la relativamente poca variación de largo plazo que tuvo en el período analizado. Otra causa puede ser el hecho de que no empleamos los tipos de cambio reales ponderados por el comercio en el análisis econométrico. Puede deberse también a problemas reflejos de agregación. Y finalmente, quizás ponga de manifiesto el hecho de que a largo plazo los factores no vinculados a los precios tienen una influencia mucho más clara sobre el comercio que las variaciones relativas de precios. En todo caso, respalda al modelo analítico expresado en la ecuación [1], lo cual indica que la evolución de largo plazo del comercio en Centroamérica ha sido determinada principalmente por factores no vinculados a los precios. Esto avala el argumento de que para impulsar las posibilidades de exportación de largo plazo en estos países es necesario intentar cambiar la composición de sus exportaciones e incluir más bienes cuya demanda, tanto mundial como local, sea altamente elástica con respecto al ingreso. En este sentido, además de evitar pérdidas en sus ventajas competitivas mediante la reducción de los precios, los aranceles y la devaluación nominal, los países en desarrollo deberían tratar de poner en práctica políticas para mejorar su destreza tecnológica, sus habilidades de innovación y sus capacidades científicas.

Finalmente, la validez empírica de la ecuación [1] puede verificarse mediante la comparación de la razón de elasticidad que surge de las ecuaciones cointegradoras con la razón entre el crecimiento medio del PIB en cada uno de los países centroamericanos y el de Estados Unidos. En todos los casos, aunque la muestra 
CUADRO 3

\section{Tres países centroamericanos: Estructura óptima de rezago de VAR con tres variables y pruebas de correlación serial residual de ecuaciones simples de importaciones ${ }^{a}$}

\begin{tabular}{|c|c|c|c|c|c|c|c|}
\hline \multirow[t]{2}{*}{ País } & \multirow[t]{2}{*}{ Variables VAR } & \multicolumn{3}{|c|}{$\begin{array}{l}\text { Diagnóstico de la prueba } \\
\text { /Orden del rezago }\end{array}$} & \multirow{2}{*}{\multicolumn{3}{|c|}{$\begin{array}{c}\text { Prueba del multiplicador } \\
\text { de Lagrange } \\
\chi^{2}(1)\end{array}$}} \\
\hline & & $\begin{array}{c}\mathrm{AC} \\
\text { /rezago }\end{array}$ & $\begin{array}{c}\mathrm{SC} \\
\text { /rezago }\end{array}$ & $\begin{array}{l}\text { ALR valor } \mathrm{p} \\
\text { /rezago elegido }\end{array}$ & & & \\
\hline \multicolumn{8}{|c|}{ Ecuación de importaciones } \\
\hline Costa Rica & JM I CDP I PEP & $1073 / 1$ & $1765 / 1$ & $034 / 1$ & $\mathrm{LM}$ & LGDP & LRER \\
\hline El Salvador & $\begin{array}{l}\text { LM, LGDP, LRER } \\
\text { LM, LGDP, LRER }\end{array}$ & $159,9 / 1$ & $148,2 / 1$ & $0,22 / 1$ & $\begin{array}{l}4,0 \\
5,5^{c}\end{array}$ & $13,9^{\mathrm{c}}$ & 2,6 \\
\hline Guatemala & LM, LGDP, LRER & $193,8 / 1$ & $183,1 / 1$ & $0,28 / 1$ & 4,3 & $10,3^{b}$ & 0,8 \\
\hline \multicolumn{8}{|c|}{ Ecuación de exportaciones } \\
\hline & & & & & LX & LNI & LRER \\
\hline Costa Rica & LX, LNI, LRER & $172,9 / 1$ & $162,2 / 1$ & $0,77 / 1$ & 0,6 & 0,6 & 0,02 \\
\hline El Salvador & LX, LNI, LRER & $180,1 / 1$ & $169,4 / 1$ & $0,88 / 1$ & 0,0 & 0,4 & 2,1 \\
\hline Guatemala & LX, LNI, LRER & $188,7 / 1$ & $176,4 / 1$ & $0,63 / 1$ & $5,2^{\mathrm{c}}$ & 0,0 & 1,1 \\
\hline
\end{tabular}

Fuente: Elaborado por los autores.

a Selección de orden óptimo de VAR según el criterio de información de Akaike (AC), el criterio de Schwartz (SC) y las razones de verosimilitudes ajustadas (ALR) calculadas con un rezago de hasta seis años.

b ALR= razón de verosimilitud ajustada.

c Significación a nivel de 5\% de confianza en los resultados de las pruebas del multiplicador de Lagrange (LM) de correlación serial residual.

CUADRO 4

Procedimiento de cointegración de Johansen con tres variables para los países centroamericanos, 1950-1999a

\begin{tabular}{|c|c|c|c|c|c|c|c|}
\hline \multirow[t]{2}{*}{ País } & \multirow[t]{2}{*}{ Rezago } & \multicolumn{4}{|c|}{$\begin{array}{l}\text { Resultados de las pruebas de } \\
\text { cointegración de Johansen }\end{array}$} & Vector de cointegración & \multirow{2}{*}{$\begin{array}{l}\text { Prueba de razón } \\
\text { de verosimilitudes } \\
\chi^{2}(1)\end{array}$} \\
\hline & & \multicolumn{5}{|c|}{ Ecuación de importaciones } & \\
\hline Costa Rica & 1 & $\begin{array}{l}\text { Ho: } \\
r=0 \\
r<1\end{array}$ & $\begin{array}{l}\mathrm{H} 1: \\
\mathrm{r}<1 \\
\mathrm{r}=2\end{array}$ & $\begin{array}{l}\text { LRS } \\
61,0 \\
10,6\end{array}$ & $\begin{array}{c}5 \% \mathrm{CV} \\
22,0 \\
15,9\end{array}$ & $\begin{array}{c}\mathrm{LM}=-\begin{array}{c}-1,32 \\
(1,40)\end{array}+1,36 \mathrm{LGDP}-0,15 \mathrm{LRER} \\
(0,07) \quad(0,32)\end{array}$ & 0,16 \\
\hline El Salvador & 1 & $\begin{array}{l}\text { Ho: } \\
r=0 \\
r<1\end{array}$ & $\begin{array}{l}\mathrm{H} 1: \\
\mathrm{r}<1 \\
\mathrm{r}=2\end{array}$ & $\begin{array}{c}\text { LRS } \\
44,4 \\
8,5\end{array}$ & $\begin{array}{c}5 \% \mathrm{CV} \\
22,0 \\
15,9\end{array}$ & $\begin{array}{c}\mathrm{LM}=-0,60+1,49 \mathrm{LGDP}-0,49 \mathrm{LRER} \\
(2,1) \quad(0,22) \quad(0,26)\end{array}$ & 2,04 \\
\hline Guatemala & 1 & $\begin{array}{l}\text { Ho: } \\
r=0 \\
r<1\end{array}$ & $\begin{array}{l}\mathrm{H} 1: \\
\mathrm{r}<1 \\
\mathrm{r}=2\end{array}$ & $\begin{array}{l}\text { LRS } \\
82,7 \\
8,6\end{array}$ & $\begin{array}{c}5 \% \mathrm{CV} \\
22,0 \\
15,9\end{array}$ & $\begin{array}{c}\mathrm{LM}=-3,3+1,27 \mathrm{LGDP}-1,09 \mathrm{LRER} \\
(1,7) \quad(0,08) \quad(0,39)\end{array}$ & $7,86^{\mathrm{b}}$ \\
\hline \multicolumn{8}{|c|}{ Ecuación de exportaciones } \\
\hline Costa Rica & 1 & $\begin{array}{l}\text { Ho: } \\
r=0 \\
r<1\end{array}$ & $\begin{array}{l}\mathrm{H} 1: \\
\mathrm{r}<1 \\
\mathrm{r}=2\end{array}$ & $\begin{array}{l}\text { LRS } \\
65,9 \\
15,6\end{array}$ & $\begin{array}{c}5 \% \mathrm{CV} \\
22,0 \\
15,9\end{array}$ & $\begin{array}{c}\mathrm{LX}=4,3+2,64 \mathrm{LGDP}-1,89 \mathrm{LRER} \\
(20,9) \quad(1,4) \quad(4,2)\end{array}$ & 0,87 \\
\hline El Salvador & 1 & $\begin{array}{l}\text { Ho: } \\
r=0 \\
r<1\end{array}$ & $\begin{array}{l}\mathrm{H} 1: \\
\mathrm{r}<1 \\
\mathrm{r}=2\end{array}$ & $\begin{array}{c}\text { LRS } \\
63,5 \\
4,7\end{array}$ & $\begin{array}{c}5 \% \mathrm{CV} \\
22,0 \\
15,9\end{array}$ & $\begin{array}{c}\mathrm{LX}=-13,8+2,24 \mathrm{LGDP}+1,43 \mathrm{LRER} \\
(6,1) \quad(0,54) \quad(0,71)\end{array}$ & 4,3 \\
\hline Guatemala & 1 & $\begin{array}{l}\text { Ho: } \\
r=0 \\
r<1\end{array}$ & $\begin{array}{l}\mathrm{H} 1: \\
\mathrm{r}<1 \\
\mathrm{r}=2\end{array}$ & $\begin{array}{l}\text { LRS } \\
60,4 \\
10,9\end{array}$ & $\begin{array}{c}5 \% \mathrm{CV} \\
22,0 \\
15,9\end{array}$ & $\begin{array}{c}\mathrm{LX}=17,8+1,07 \mathrm{LGDP}-3,51 \mathrm{LRER} \\
(18,4) \quad(0,47) \quad(3,6)\end{array}$ & 2,5 \\
\hline
\end{tabular}

Fuente: Elaborado por los autores.

a Los valores entre paréntesis en la cuarta columna corresponden a los errores estándares asintóticos. La prueba de razón de verosimilitudes $\chi^{2}(1)$ en la quinta columna hace referencia al $\chi^{2}$ con un grado de libertad según la hipótesis nula en la que los términos del parámetro de comercio en el vector de cointegración es igual a cero.

b Significación a nivel de $5 \%$ de confianza. 
CUADRO 5

Tres países centroamericanos: Elasticidad ingreso de las importaciones y exportaciones y la razón de crecimiento,1950-1999a

\begin{tabular}{lcccc}
\hline País & $\begin{array}{c}\text { Elasticidad ingreso de } \\
\text { las importaciones }\end{array}$ & $\begin{array}{c}\text { Elasticidad ingreso de } \\
\text { las exportaciones }\end{array}$ & $\begin{array}{c}\text { Razón de elasticidad } \\
\left(b_{y} / a_{y}\right)\end{array}$ & $\begin{array}{c}\text { Razón de crecimiento } \\
\left(y / y_{r w}\right)\end{array}$ \\
\hline Costa Rica & 1,36 & 2,64 & 1,94 & 1,50 \\
El Salvador & 1,49 & 2,24 & 1,50 & 1,03 \\
Guatemala & 1,20 & 1,07 & 0,89 & 1,11 \\
\hline
\end{tabular}

Fuente: Cuadros 2 a 4.

a La razón de elasticidad también se expresa como $\pi / \xi$ en la sección II, ecuación [1].

incluya el efecto de Integrated Electronics (INTEL) en el caso de Costa Rica (véase más adelante la sección VI, apartado 2), la razón de elasticidades exportación- importación se aproxima a la de crecimiento, lo cual indica, hasta cierto punto, la existencia de una relación de largo plazo entre ambas magnitudes.

\section{V}

\section{Liberalización del comercio y evolución del comercio exterior}

\section{El comportamiento de la elasticidad ingreso de las importaciones y las exportaciones}

En la sección anterior se hizo una estimación de las elasticidades ingreso de largo plazo de las funciones de demanda de exportación e importación. Utilizando la ecuación [1] se comparó la razón de las elasticidades con la razón de crecimiento medio de largo plazo. En un esfuerzo por arrojar luz sobre la relación existente entre el potencial de crecimiento económico y los cambios de los regímenes comerciales, examinamos el comportamiento a lo largo del tiempo de las elasticidades ingreso de importaciones y exportaciones.

Más específicamente, el ejercicio consiste en cambiar recursivamente la amplitud del dominio temporal de la muestra que se emplea en los cálculos econométricos a fin de relacionar las variaciones de los parámetros de elasticidad con los cambios en la orientación del comercio y, en general, de la política económica. En este sentido una desviación visible, digamos, en las elasticidades ingreso de importación y/o exportación puede reflejar la adopción de políticas orientadas hacia el exterior, cambios en la estructura productiva o una combinación de ambas cosas. En este ejercicio, se eligió el año 1986 como el de demarcación crítica de un cambio en el régimen de comercio: del proteccionis- mo a la adopción de políticas de liberalización del comercio. Fue elegido ese año porque marca el comienzo de la Ronda Uruguay (1986-1994).

La Ronda Uruguay implicó un cambio decisivo en la concepción de las relaciones comerciales. Aun cuando los países no se convirtieron de inmediato en miembros del Acuerdo General sobre Aranceles Aduaneros y Comercio (GATT), la mayoría de ellos aceptó que, cualquiera fuese su nivel de desarrollo, debían adherir a los principios, normas y obligaciones que un convenio multilateral de libre comercio requiere. En consonancia con esta tendencia general, Centroamérica comenzó a derribar gradualmente las barreras comerciales. ${ }^{9}$

Siguiendo tal metodología, se aplicaron las ecuaciones cointegradoras para importaciones y exportaciones a todos los países estudiados en un número fijo de observaciones que llegó a 30, tomando 1950-1980 como el período inicial y 1969-1999 como

\footnotetext{
${ }^{9}$ Costa Rica se convirtió en miembro del GatT en 1990; El Salvador y Guatemala lo hicieron en 1991. Sin embargo, el comienzo de sus procesos de reforma comercial precede a su adhesión formal al GATT. Esto se muestra, para el caso de Costa Rica, en el apéndice B, que muestra una lista de medidas de reforma comercial desde 1984 hasta 1988
} 
el período final. ${ }^{10}$ Del cálculo de estas ecuaciones surgió una serie de 19 observaciones para las elasticidades ingreso de importaciones y exportaciones de Costa Rica, El Salvador y Guatemala, que figuran en los gráficos 1 a 4 .

Los gráficos 1 a 4 muestran, en primer lugar, que la elasticidad ingreso de las importaciones es más estable a lo largo del tiempo que la elasticidad ingreso de las exportaciones; ${ }^{11}$ también cuestionan la medida en que las políticas de exportación efectivamente tienen consecuencias precisas y predecibles. Segundo, la liberalización del comercio parece haber alterado la relación entre ambos parámetros en dos de los tres casos estudiados: El Salvador y Guatemala (cuadro 6). En todos los casos estas políticas se hallan vinculadas a un aumento de la elasticidad ingreso de las importaciones por encima del de la elasticidad ingreso de las exportaciones. Tanto en El Salvador como en Guatemala el cambio de tendencia de ambos parámetros ocurre en el mismo punto final (1994). En Costa Rica las políticas de liberalización del comercio no afectaron la propensión a exportar e importar, en tanto la razón de elasticidad permaneció constante (cuadro 6).

En tercer lugar, el cambio en la composición de las exportaciones destinadas al principal socio comercial — de productos primarios a productos manufacturados o bienes altamente tecnológicos- altera la elasticidad ingreso de las exportaciones. El ejemplo más extremo es el de Costa Rica en el último período estimado (1969-1999), que incluye los efectos sobre el comportamiento del comercio que tuvo la puesta en marcha de la planta de INTEL, precisamente en 1999 (gráfico 1). ${ }^{12}$ El resultado entre el período 1968-1998 y 1969-1999 fue que la elasticidad ingreso de las exportaciones aumentó de 1,96 a 3,59. Por su parte, la elasticidad ingreso de las importaciones disminuyó de 1,43 a 1,11 . Una ojeada a los gráficos 2 y 3 da lugar a conclusiones semejantes respecto de El Salvador y

Costa Rica: Elasticidades ingreso de las importaciones y de las exportaciones

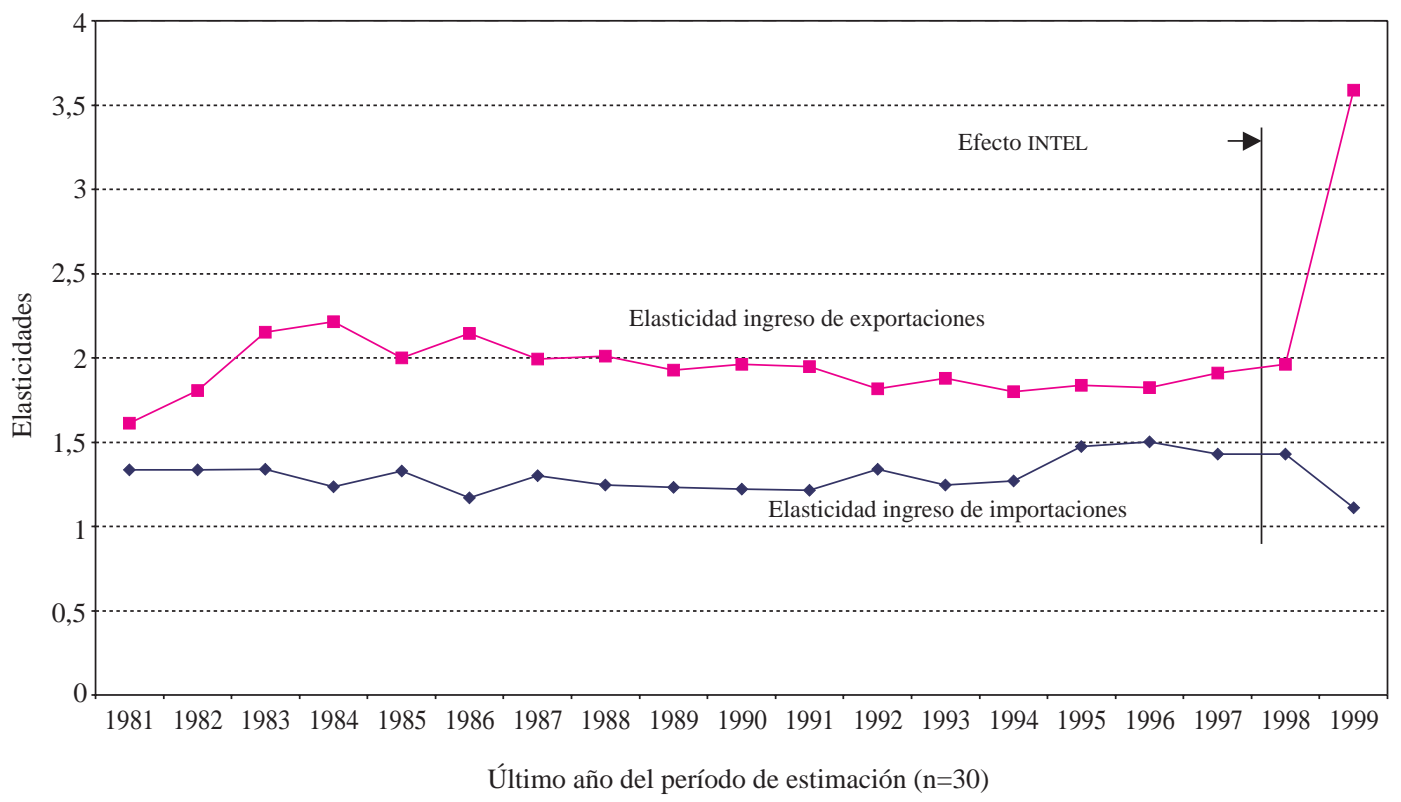

\footnotetext{
${ }^{10}$ Puede llevarse a cabo un ejercicio idéntico empleando una muestra de menor tamaño, pero para hacerlo se requeriría un conjunto diferente de técnicas econométricas.

${ }^{11}$ Esto convalida cálculos anteriores de ambos parámetros obtenidos para diferentes períodos y para un conjunto de economías en desarrollo e industrializadas (Hieke, 1977).

12 En el otro extremo del espectro otras actividades de zonas de libre comercio, como las textiles, tienen un bajo componente de valor agregado. Sin embargo, debe insistirse en que esto sólo se
}

refiere al componente de valor agregado de sus productos de exportación. Ésta es la contribución directa de las zonas de libre comercio a la generación de valor agregado. Sin embargo, también hay un efecto indirecto que no puede excluirse: es el referente a los ingresos en moneda extranjera de las zonas de libre comercio que de hecho pueden invertirse en otras actividades de alto valor agregado. La ley de Thirlwall se refiere principalmente a la importancia de tener acceso a divisas para promover la inversión y el crecimiento. 
El Salvador: Elasticidades ingreso de las importaciones y de las exportaciones

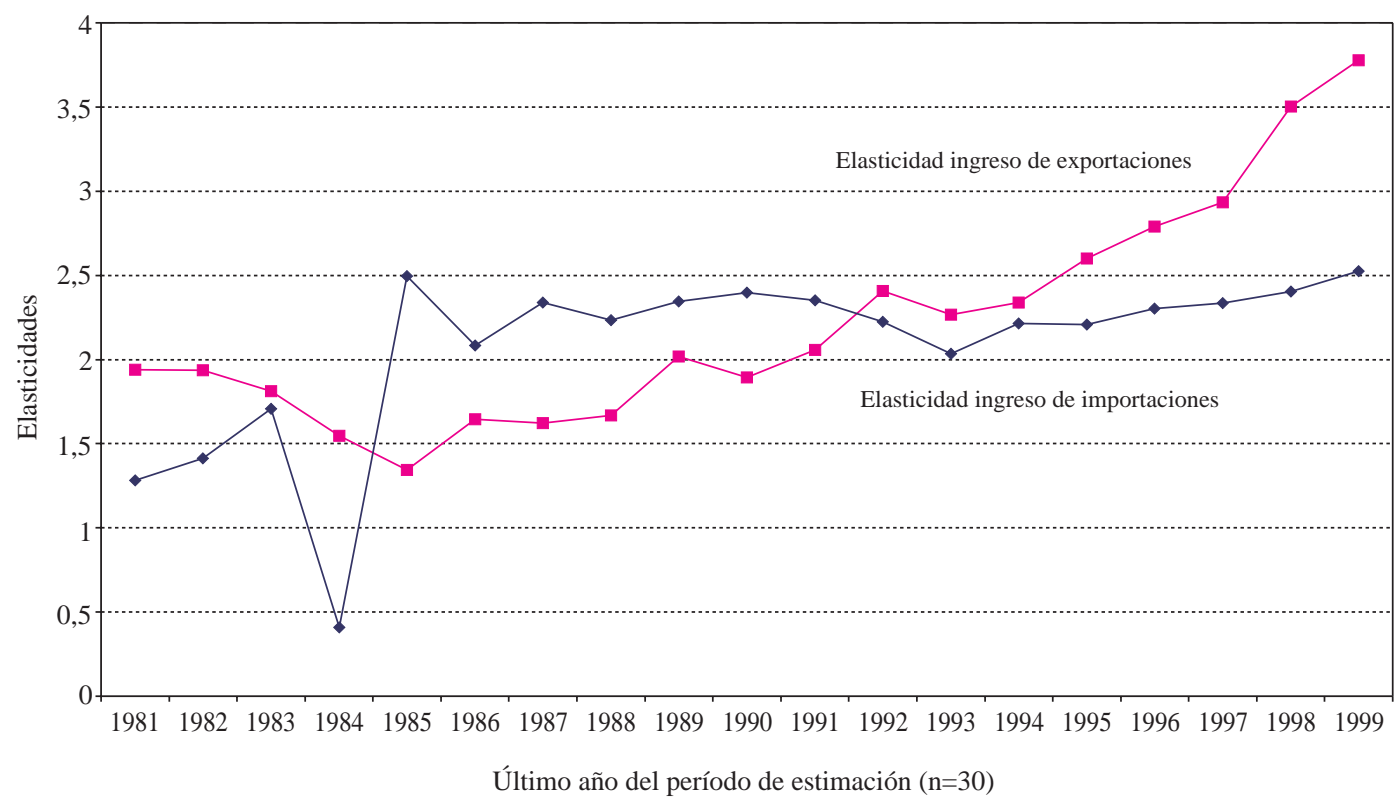

GRAFICO 3

Guatemala: Elasticidades ingreso de las importaciones y de las exportaciones

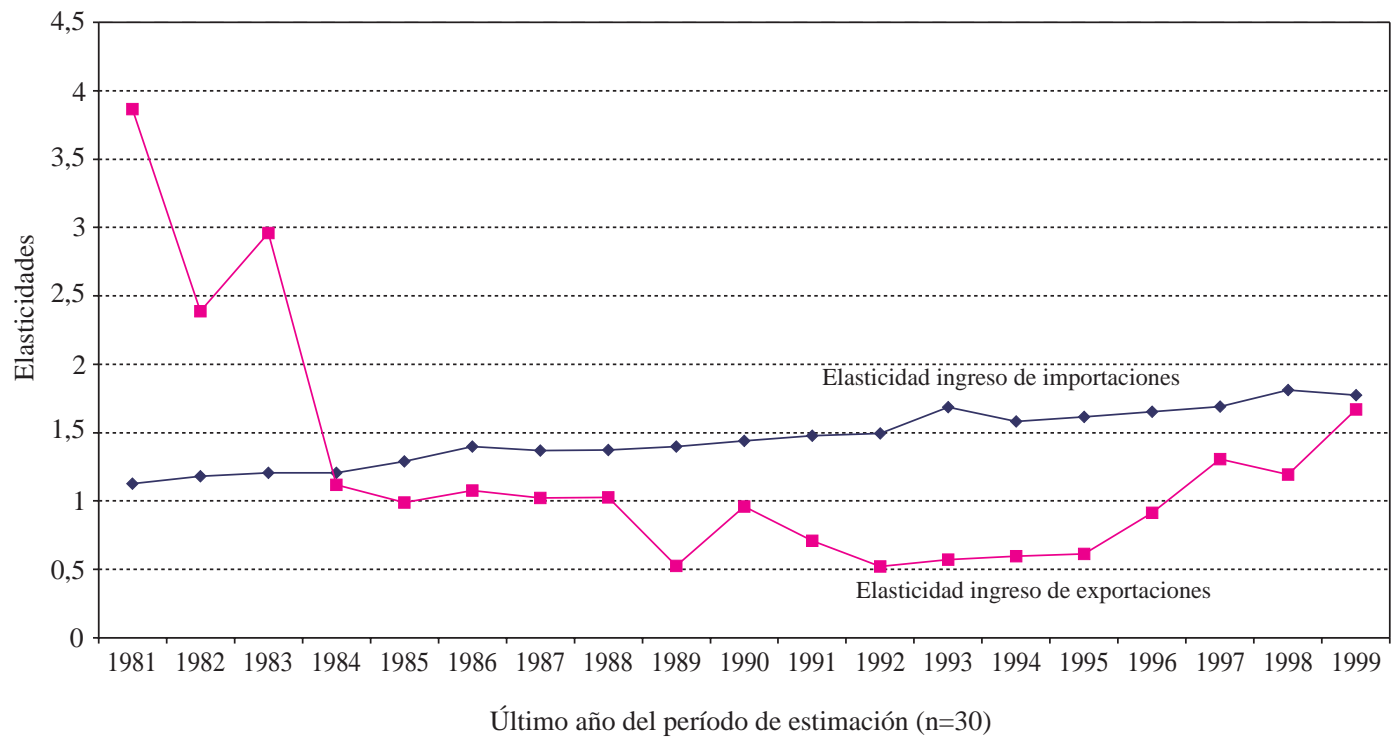

Guatemala. Para ambos países los períodos sujetos a estimación que incluyen la década de 1990 muestran un aumento de la elasticidad ingreso de las exportaciones que coincide con un cambio en la composición de las exportaciones, de productos agrícolas a productos manufacturados (cuadro 7)

No obstante, tanto en El Salvador como en Guatemala el aumento en la elasticidad ingreso de las ex- portaciones no alcanza a compensar el aumento de la elasticidad ingreso de las importaciones. Como se advierte en el cuadro 6, la razón de elasticidad disminuye durante el período de liberalización del comercio. Además, en el caso de Guatemala este esquema se ve reforzado durante el período de promoción de las exportaciones, lo cual indica la tendencia de esta economía a rezagarse con respecto a su principal socio 
Costa Rica, El Salvador y Guatemala: Elasticidades ingreso de las importaciones normalizadas

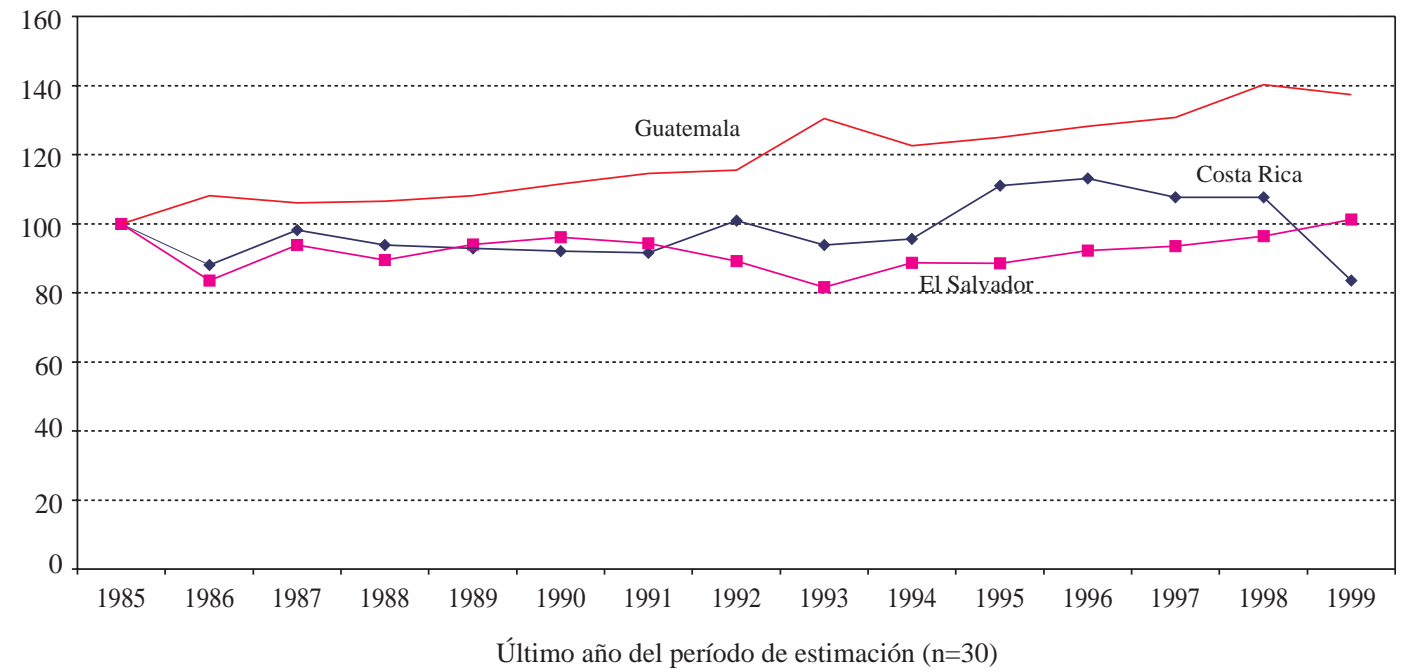

CUADRO 6

Tres países centroamericanos: Razón entre la elasticidad ingreso de la exportación y la elasticidad ingreso de la importación

\begin{tabular}{lcccc}
\hline & Proteccionismo & & \multicolumn{2}{c}{ Liberalización del comercio } \\
\cline { 2 - 3 } & Antes de 1986 & & 1986-1991 & $1992-1999$ \\
\hline Costa Rica & 1,5 & & 1,6 & 1,6 \\
El Salvador & 1,9 & 0,7 & 1,2 \\
Guatemala & 2,2 & 0,7 & 0,5 \\
\hline
\end{tabular}

Fuente: Cálculos de los autores sobre la base de cifras oficiales.

comercial. Más allá de las consecuencias inmediatas que subrayan la relación entre el crecimiento, la exportación y las elasticidades ingreso, estos resultados revelan una consecuencia ulterior y más fundamental: la de un proceso de divergencia entre las tasas de crecimiento de las economías de Centroamérica a medida que se integran en la economía mundial.

\section{Comercio y convergencia}

El modelo expuesto en la sección II postula la existencia de una relación proporcional de largo plazo entre la razón de las elasticidades ingreso de las exportaciones y de las importaciones de un país, y la razón de su crecimiento económico en relación con el del resto del mundo. Los resultados empíricos que muestran los gráficos 1 a 4 y el cuadro 7 indican que la razón entre las elasticidades ingreso de las exportaciones y de las importaciones no cambió sistemáticamente durante la
CUADRO 7

Tres países centroamericanos: Composición porcentual de los principales productos exportados a Estados Unidos, 1990-1999

\begin{tabular}{llrrrr}
\hline Países & Productos & \multicolumn{4}{c}{ Años } \\
\cline { 2 - 5 } & & 1990 & 1993 & 1996 & 1999 \\
\hline \multirow{2}{*}{ Costa Rica } & Maquinaria & 0,2 & 0,4 & 0,3 & 37,4 \\
& Frutas y frutos secos & 22,8 & 22,4 & 20,0 & 13,0 \\
& Textiles & 37,4 & 41,2 & 35,5 & 20,8 \\
& Maquinaria eléctrica & 4,4 & 5,3 & 7,8 & 6,5 \\
& Subtotal & 64,8 & 69,3 & 63,6 & 77,7 \\
& & & & \\
El Salvador & Textiles & 22,8 & 51,5 & 67,2 & 82,8 \\
& Café y té & 36,1 & 20,2 & 4,9 & 4,2 \\
& Maquinaria eléctrica & 10,3 & 6,5 & 3,1 & 1,9 \\
& Pescado y crustáceos & 5,2 & 4,3 & 3,7 & 1,7 \\
& Subtotal & 74,4 & 82,5 & 78,9 & 90,6 \\
& & & & & \\
Guatemalay & Textiles & 24,0 & 45,8 & 47,7 & 54,9 \\
& Café & 23,7 & 12,9 & 15,6 & 13,4 \\
& Frutas y frutos secos & 15,3 & 11,6 & 10,8 & 8,6 \\
& Combustibles minerales & 2,9 & 2,0 & 3,6 & 4,2 \\
& Subtotal & 65,9 & 72,3 & 77,7 & 81,1 \\
\hline
\end{tabular}

Fuente: Cálculos de los autores con datos proporcionados por la CEPAL.

aplicación de las políticas de liberalización comercial. Como resultado de ello, los países se vieron imposibilitados de aumentar su potencial de crecimiento económico y, por ende, el bienestar de su población.

En el caso de Costa Rica, la elasticidad ingreso de las exportaciones a lo largo de todo el período de estimación elegido continuó situándose por sobre la elasticidad ingreso de las importaciones. Esta tendencia se vio acentuada en un período de estimación más 
CUADRO 8

Centroamérica y Estados Unidos: Coeficientes de correlación entre las diferencias en sus tasas de crecimiento, 1950-1999

\begin{tabular}{lcccccc}
\hline Variables de correlación $^{\mathrm{a}}$ & $1950-1960$ & $1960-1970$ & $1970-1980$ & $1980-1990$ & $1990-1999$ \\
\hline DCRG, USG & 0,26 & 0,24 & 0,37 & 0,58 & 0,42 \\
DCREL, USG & 0,09 & $-0,24$ & $-0,04$ & 0,07 & 0,51 \\
\hline
\end{tabular}

Fuente: Cálculos de los autores.

a DCRG = diferencia entre la tasa de crecimiento de Costa Rica y la de Guatemala; DCREL= diferencia entre la tasa de crecimiento de Costa Rica y la de El Salvador; USG= tasa de crecimiento de Estados Unidos.

reciente (finalizado en 1999), cuando Costa Rica comenzó a exportar bienes con mayor valor agregado, como componentes electrónicos, en virtud de la instalación de la planta de INTEL.

En los casos de El Salvador y Guatemala, en el período de liberalización del comercio (es decir, a partir de la segunda mitad de la década de 1980) se registró una reducción de la razón entre las elasticidades ingreso de las exportaciones y de las importaciones, lo cual indica que, unido a otros factores como acontecimientos adversos externos y conflictos internos, ese proceso no alivió la tensión de la balanza de pagos, sino que quizás la haya vuelto más restrictiva, limitando así aún más el potencial de crecimiento económico de largo plazo de esos países. No obstante, después de los procesos de diversificación de las exportaciones de principios de la década de 1990, El Salvador fue el único país que logró revertir la tendencia de esa razón y capitalizar el dinamismo de su desempeño externo.

Los resultados descritos indican que la expansión de la demanda externa que puede seguir al proceso de integración regional debido a la disminución de las barreras arancelarias y no arancelarias y del tratamiento asimétrico, puede de hecho conducir, en ausencia de políticas de compensación, a un proceso de

\section{VI}

\section{Conclusiones}

En este artículo se analiza la relación entre la evolución de las exportaciones y el crecimiento económico, utilizando un modelo restringido de crecimiento de la balanza de pagos. En pocas palabras, desde nuestra perspectiva se establece que el crecimiento económico de un país se ve determinado fundamentalmente por divergencia del crecimiento entre los tres países centroamericanos que se tratan en el presente estudio. Por la mera lógica del modelo expuesto en la sección II, un aumento de la demanda externa, no compensado por una disminución de la demanda de los sectores no exportadores, aumentará las tasas de crecimiento de las economías de Centroamérica. Pero, dadas las diferencias en la razón entre las elasticidades ingreso de las exportaciones y de las importaciones, su potencial de crecimiento se elevará en proporciones diferentes.

Para examinar las bases empíricas de esta hipótesis, los coeficientes de correlación entre la tasa de crecimiento del ingreso nacional estadounidense y las diferencias de las tasas de crecimiento de Costa Rica, por un lado, y de Guatemala y El Salvador, por otro, se calcularon sobre una base decenal para el período 1950-1999. Como se muestra en el cuadro 8, en todos los casos los coeficientes de correlación aumentaron a partir de 1980 y arrojaron valores positivos. Este resultado sugiere además una vinculación directa entre la expansión de la demanda externa y la divergencia dentro de Centroamérica, donde Costa Rica está cerrando rápidamente la brecha con Estados Unidos, quedando los demás considerablemente rezagados.

dos factores: i) el efecto de la elasticidad ingreso del resto del mundo con respecto a las exportaciones del país, y ii) la elasticidad ingreso de las importaciones del propio país. El modelo de balanza de pagos tiene una incidencia importante en las negociaciones comerciales y en las propuestas de liberalización del comercio 
que pueden resultar de estas negociaciones. En particular, establece que las barreras arancelarias y no arancelarias al comercio exterior generarán una mejora para las posibilidades de crecimiento económico del país si el impulso del sector exportador compensa ampliamente una desaceleración en el sector no exportador.

Durante el período comprendido en este estudio, los países centroamericanos adoptaron regímenes variados de política comercial y al mismo tiempo sufrieron los efectos de una serie de perturbaciones externas, acontecimientos imprevistos y cambios internos repentinos en la política económica. A pesar de ello, las relaciones econométricas que aquí se presentan muestran una relación proporcional de largo plazo entre la razón de elasticidades importación-exportación de Centroamérica, y la razón existente entre las tasas de crecimiento del ingreso de Centroamérica y las de Estados Unidos. Además, los resultados expuestos relativos a Centroamérica también indican que la liberalización del comercio ha tenido resultados bastante diferentes en los casos aquí analizados.

La experiencia de Costa Rica es la que ha mostrado resultados más satisfactorios. Sus estrategias de liberalización del comercio y de promoción de las exportaciones están relacionadas con una mejora de la demanda externa y una caída relativa de poca significación en el sector interno que compite con las importaciones. De esta manera, sus posibilidades de crecimiento económico mejoraron.

La experiencia de los otros dos países de la región no ha sido tan positiva. En El Salvador y Guatemala la liberalización del comercio no ha aliviado las limitaciones externas a sus trayectorias de crecimiento económico. Es importante señalar que, en vista de sus historias económicas, en ambos casos la liberalización del comercio puede haber funcionado como un factor agravante de su desganado desempeño económico.
El problema más importante, desde la perspectiva de las políticas, es de qué manera garantizar que los acuerdos comerciales y la liberalización del comercio den impulso al crecimiento económico. En este sentido, los resultados econométricos aquí presentados indican que el potencial de crecimiento de largo plazo de los países centroamericanos puede mejorar si estos modifican la composición de sus productos transables, integrando más bienes cuya demanda mundial y local sea altamente elástica con respecto al ingreso. Por lo tanto, los países deberían asegurarse de que las negociaciones comerciales se transformen en un vehículo para integrar a su estrategia aquellas políticas que mejoren su destreza tecnológica, sus habilidades de innovación y sus capacidades científicas.

Como ya hemos mostrado, las diferencias estructurales en las respuestas de las tres economías centroamericanas estudiadas ante los procesos de liberalización del comercio pueden tener implicaciones importantes en el posible impacto de un ALCA sobre la tendencia a la convergencia en sus trayectorias de crecimiento. En efecto, se ha visto que, junto con otros factores, en las últimas dos décadas en las que se comenzó a poner en práctica la liberalización económica, la ampliación de la demanda de Estados Unidos ha tendido a acentuar la brecha entre Costa Rica y los demás países centroamericanos. Estos resultados indican que la expansión exógena de la demanda externa puede conducir a intensificar un crecimiento económico divergente dentro de Centroamérica. A partir de esta conclusión podría pensarse que el acuerdo de libre comercio por sí solo puede no ser suficiente para asegurar la convergencia y un crecimiento económico más rápido en Centroamérica.

(Traducido del inglés, incluidos los apéndices) 
APENDICE A

Tres países centroamericanos: Indicadores macroeconómicos, 1950-1999

(Tasas anuales medias de crecimiento)

\begin{tabular}{llll}
\hline Variables & Costa Rica & El Salvador
\end{tabular}

PIB

Exportaciones

Importaciones

Déficit de cuenta corriente, en porcentaje del PIB

Tipo de cambio real

4,9
6,8
6,6
4
0,6

PIB

Exportaciones

Importaciones

Déficit de cuenta corriente, en porcentaje del PIB

Tipo de cambio real
6,0

6,2

8,5

$-2,4$

0,1

5,5

4,7

6,3

$-6,0$

0,0

1950-1999

Exportaciones

Importaciones

Déficit de cuenta corriente, en porcentaje del PIB

Tipo de cambio real

\section{3,5}

4,7

6,3

1,4

2,3

3,7

4,4

4,9

2,9

0,1

1950-1970

$\begin{array}{rr}4,9 & 4,1 \\ 5,3 & 4,1 \\ 6,2 & 4,1 \\ -0,4 & -2,3 \\ -0,4 & 0,5\end{array}$

1970-1980

$\begin{array}{rr}3,0 & 5,4 \\ 4,6 & 6,9 \\ 3,7 & 6,8 \\ -1,0 & -1,8 \\ -1,7 & -0,7\end{array}$

1980-1990

PIB

$-0,8$

0,9

5,7

$-3,8$

$-2,4$

Importaciones

1,8

$-4,9$

Déficit de cuenta corriente, en porcentaje del PIB

$-3,1$

$-3,7$

$-2,9$

1990-1999

PIB

Exportaciones

5,0

10,7

4,6

12,0

4,1

8,4

6,4

Importaciones

$-4,3$

12,7

8,8

Déficit de cuenta corriente, en porcentaje del PIB

$-1,3$

Tipo de cambio real

$-2,7$

$-2,0$

Fuente: Datos calculados por los autores sobre la base de cifras oficiales y de la CEPAL. 
APENDICE B

Costa Rica: Algunas medidas de reforma relacionadas con la liberalización del comercio en las décadas de 1980 y 1990

Año Medidas

1984 Ley de equilibrio fiscal en el sector privado. Esta ley incorpora el fomento de las exportaciones mediante tres regímenes de exportación: contratos de exportación, admisión temporal y zonas francas

1985 Código Aduanero Centroamericano. Los aranceles aduaneros de importación van de $1 \%$ a $100 \%$

1986 Primer programa de ajuste estructural. El programa incluye la reducción progresiva de los aranceles sobre productos importados y la eliminación de las restricciones de cantidad

1987 Se reducen los depósitos por importaciones de 50\% a 10\% y finalmente se eliminan en 1992

1989 Segundo programa de ajuste estructural. El programa busca unificar los derechos de importación en una escala arancelaria de $5 \%$ a $40 \%$. Brinda un programa de reducción progresiva de los límites arancelarios máximos

1989 El 10\% de impuesto ad valórem sobre las ganancias relativas al café se modifica para quedar entre el $2,5 \%$ y el $10 \%$

1990 Costa Rica se integra al GATT. En cumplimiento de las normas del GATT acuerda reemplazar por aranceles las restricciones de cantidad para las importaciones de algunos productos. Esos aranceles se ubican entre el 55\% y el $274 \%$. Entre tales productos se incluyen productos agrícolas. Se aplican cuotas arancelarias a dos productos agrícolas: pollo trozado y productos lácteos

1992 Se elimina el recargo a las importaciones del Banco Central, que se ubicaba entre $0 \%$ y $100 \%$

1992 Ley de Regulación de todas las exoneraciones tributarias y sus excepciones (Ley N 7293 ) que elimina la mayoría de las exenciones al pago de impuestos, incluso impuestos que gravan las importaciones

1994 Se reduce a $1 \%$ el impuesto de $3 \%$ que grava todas las importaciones

1995-1996 Parámetros del Arancel Externo Común Centroamericano. 0\% para materias primas y bienes de capital, 5\% y $10 \%$ para insumos intermedios y $20 \%$ para productos finales. Se reduce el límite máximo de $20 \%$ a $15 \%$ en el año 1997

1996 Se sustituyen los regímenes de contratos de exportación y admisión temporal por un régimen devolutivo de derechos y régimen de perfeccionamiento activo

1997 Costa Rica adopta un programa de reducción definitiva de aranceles con el objetivo de llegar a un límite máximo de $15 \%$ en el año 2000

1998 En julio de 1999 las autoridades aplican el programa de arancel externo común mediante la reducción de los aranceles para bienes intermedios de $16 \%$ a $15 \%$

Fuente: Elaborado por los autores. 
APENDICE C

Estimación de las elasticidades ${ }^{a}$

\begin{tabular}{lllllll}
\hline Año & IEICR & EEICR & IEIEL & EEIEL & IEIG & EEIG \\
\hline 1981 & 1,3346 & 1,6132 & 1,2807 & 1,9383 & 1,1284 & 3,8641 \\
1982 & 1,3354 & 1,8078 & 1,4131 & 1,9358 & 1,1799 & 2,388 \\
1983 & 1,3391 & 2,1518 & 1,7063 & 1,813 & 1,2068 & 2,9595 \\
1984 & 1,2341 & 2,2144 & 0,40724 & 1,5464 & 1,2054 & 1,1191 \\
1985 & 1,3273 & 1,9984 & 2,4947 & 1,3458 & 1,2917 & 0,98767 \\
1986 & 1,1694 & 2,1439 & 2,083 & 1,6452 & 1,3971 & 1,0782 \\
1987 & 1,3026 & 1,9934 & 2,3401 & 1,6233 & 1,37 & 1,0248 \\
1988 & 1,2462 & 2,0119 & 2,2333 & 1,6683 & 1,3749 & 1,0255 \\
1989 & 1,2315 & 1,9259 & 2,344 & 2,017 & 1,3969 & 0,52705 \\
1990 & 1,2212 & 1,961 & 2,3982 & 1,8938 & 1,441 & 0,96059 \\
1991 & 1,2151 & 1,9478 & 2,3511 & 2,058 & 1,4786 & 0,71146 \\
1992 & 1,34 & 1,8168 & 2,2228 & 2,4079 & 1,4924 & 0,52329 \\
1993 & 1,2442 & 1,8783 & 2,0358 & 2,2666 & 1,6847 & 0,57335 \\
1994 & 1,2691 & 1,801 & 2,2128 & 2,3393 & 1,5831 & 0,59729 \\
1995 & 1,4726 & 1,839 & 2,2092 & 2,6002 & 1,6141 & 0,61551 \\
1996 & 1,5018 & 1,8219 & 2,3019 & 2,7889 & 1,6549 & 0,91555 \\
1997 & 1,4296 & 1,9099 & 2,3339 & 2,9328 & 1,6893 & 1,3046 \\
1998 & 1,4289 & 1,9611 & 2,4029 & 3,5019 & 1,8124 & 1,1948 \\
1999 & 1,1096 & 3,5884 & 2,5243 & 3,7771 & 1,775 & 1,6678 \\
\hline
\end{tabular}

a IEICR: elasticidad ingreso de las importaciones, Costa Rica. EEICR: elasticidad ingreso de las exportaciones, Costa Rica IEIEL: elasticidad ingreso de las importaciones, El Salvador.

EEIEL: elasticidad ingreso de las exportaciones, El Salvador IEIG: elasticidad ingreso de las importaciones, Guatemala. EEIG: elasticidad ingreso de las exportaciones, Guatemala.

APENDICE D

Elasticidad ingreso de las importaciones normalizada ${ }^{a}$

\begin{tabular}{rlllrrr}
\hline Año & IEICR & IEIEL & IEIG & IEICR & IEIEL & IEIG \\
\hline 1985 & 1,3273 & 2,4947 & 1,2917 & 100 & 100 & 100 \\
1986 & 1,1694 & 2,083 & 1,3971 & 88,1037 & 83,4970 & 108,1598 \\
1987 & 1,3026 & 2,3401 & 1,37 & 98,1391 & 93,8029 & 106,0618 \\
1988 & 1,2462 & 2,2333 & 1,3749 & 93,8899 & 89,5218 & 106,4411 \\
1989 & 1,2315 & 2,344 & 1,3969 & 92,7823 & 93,9592 & 108,1443 \\
1990 & 1,2212 & 2,3982 & 1,441 & 92,0063 & 96,1318 & 111,5584 \\
1991 & 1,2151 & 2,3511 & 1,4786 & 91,5467 & 94,2438 & 114,4693 \\
1992 & 1,34 & 2,2228 & 1,4924 & 100,9568 & 89,1009 & 115,5377 \\
1993 & 1,2442 & 2,0358 & 1,6847 & 93,7392 & 81,6050 & 130,4250 \\
1994 & 1,2691 & 2,2128 & 1,5831 & 95,6152 & 88,7000 & 122,5594 \\
1995 & 1,4726 & 2,2092 & 1,6141 & 110,9470 & 88,5557 & 124,9594 \\
1996 & 1,5018 & 2,3019 & 1,6549 & 113,1470 & 92,2716 & 128,1180 \\
1997 & 1,4296 & 2,3339 & 1,6893 & 107,7074 & 93,5543 & 130,7811 \\
1998 & 1,4289 & 2,4029 & 1,8124 & 107,6546 & 96,3202 & 140,3112 \\
1999 & 1,1096 & 2,5243 & 1,775 & 83,5983 & 101,1865 & 137,4158 \\
\hline
\end{tabular}

Fuente: Elaborado por los autores.

a IEICR: elasticidad ingreso de las importaciones, Costa Rica.

IEIEL: elasticidad ingreso de las importaciones, El Salvador.

IEIG: elasticidad ingreso de las importaciones, Guatemala. 


\section{Bibliografía}

Barbosa, N. (2002): The Balance-of-Payments Constraint: From Balanced Trade to Sustainable Debt, CEPA Working Papers, No 2001-06, Nueva York, Centro de Análisis de Políticas Económicas.

Bulmer-Thomas, V. y A.D. Kincaid (2000): Central America 2020: Towards a New Regional Development Model, Hamburgo, Institut für Iberoamerika-Kunde.

Charemza, W.W. y F.D. Deadman (1992): New Directions in Econometric Practice: General to Specific Modelling, Cointegration and Vector Autoregression, Brookfield, Edward Elgar.

Cuarta Reunión Ministerial de Comercio, Cumbre de las Américas (1998): Declaración conjunta, San José, Costa Rica, 19 de marzo.

Cuthbertson, K., S.G. Hall y M.P. Taylor (1992): Applied Econometric Techniques, Ann Arbor, University of Michigan Press.

Enders, W. (1995): Applied Econometric Time Series, Nueva York, John Wiley \& Sons.

Goldstein, M. y M. Kahn (1985): Income and price effects in foreign trade, en J.W. Ronald y P.B. Kenen (comps.), Handbook of International Economics, vol. 2, Nueva York, North Holland.

Hieke, H. (1997): Balance of payments constrained growth: a reconsideration of the evidence for the U.S. economy, Journal of Post Keynesian Economics, vol. 19, № 3, Nueva York, M.E. Sharpe.

McCombie, J.S.L. y A. Thirlwall (1997): Economic growth and the balance-of-payments constraint revisited, en P. Arestis y otros (comps.), Markets, Unemployment and Economic Policy, Nueva York, Routledge.

Moreno-Brid, J.C. (1998-99): On capital flows and the balance-ofpayments constrained growth model, Journal of Post Keynesian Economics, vol. 21, N ${ }^{\circ}$, Nueva York, M.E. Sharpe.

(2001): Essays on Economic Growth and the Balance of Payments Constraint, with Special Reference to the Case of Mexico, Cambridge, Reino Unido, Universidad de Cambridge.

Moreno-Brid, J.C. y E. Pérez (1999): Balance-of-payments-constrained growth in Central America: 1950-1996, Journal of Post Keynesian Economics, vol. 22, № 1, Nueva York, M.E. Sharpe.

Quinta Reunión Ministerial de Comercio, Area de Libre Comercio de las Américas (1999): Declaración Ministerial de Toronto, Toronto, Canadá, 4 de noviembre.

Thirlwall, A.P. (1979): The balance of payments constraint as an explanation of international growth rates differences, Banca Nazionale del Lavoro Quarterly Review, No 128, Roma. 